\title{
Acute left main occlusion during transcatheter aortic valve implantation
}

\author{
Ostre zamknięcie pnia głównego lewej tętnicy wieńcowej podczas TAVI
}

\author{
Paweł Kleczyński ${ }^{1}$, Adam Witkowski ${ }^{2}$, Jarosław Trębacz ${ }^{3}$, Danuta Sorysz ${ }^{1}$, tukasz Rzeszutko ${ }^{3}$, \\ Robert Sobczyński ${ }^{4}$, Artur Dziewierz ${ }^{1}$, Krzysztof Żmudka ${ }^{3}$, Jerzy Sadowski ${ }^{4}$, Dariusz Dudek ${ }^{3}$ \\ $12^{\text {nd }}$ Department of Cardiology, Jagiellonian University Medical College, Krakow, Poland \\ ${ }^{2}$ Department of Interventional Cardiology, Institute of Cardiology, Warsaw, Poland \\ ${ }^{3}$ Department of Interventional Cardiology, Jagiellonian University Medical College, Krakow, Poland \\ ${ }^{4}$ Department of Cardiac Surgery, Jagiellonian University Medical College, Krakow, Poland
}

\begin{abstract}
A bstract
We present a case of a 92 year-old female with severe aortic stenosis who underwent TAVI. The procedure resulted with acute left main coronary artery occlusion requiring an immediate percutaneous coronary intervention.

Key words: aortic stenosis, transcatheter aortic valve implantation, left main occlusion, percutaneous coronary intervention
\end{abstract}

Kardiol Pol 2013; 71, 6: 653-655

Transcatheter aortic valve implantation (TAVI) is a highly effective procedure for selected patients who are at high risk for aortic valve replacement [1-4]. However, the incidence of severe complications is still relevant [5]. Coronary occlusion during TAVI is a life-threatening complication that requires immediate diagnosis and treatment [6].

The patient was a 92 year-old female with severe symptomatic aortic stenosis and symptoms of chronic heart failure (class III according to the New York Heart Association functional classification). The presence of many comorbidities including arterial hypertension, diabetes mellitus treated with insulin, chronic obstructive pulmonary disease, and pulmonary hypertension contributed to the logistic Euroscore I of $55 \%$ and Society of Thoracic Surgeons score of $12 \%$. An echocardiographic assessment revealed a preserved left ventricle ejection fraction of $60 \%$; mild hypertrophy of the ventricle walls; tricuspid, severely calcified aortic valve with valvular gradient 99/59 mm Hg and aortic valve area of $0.6 \mathrm{~cm}^{2}$. Systolic pressure in the right ventricle was estimated at $60 \mathrm{~mm} \mathrm{Hg}$. In transoesophageal echocardiographic (TEE) assessment, the aortic annulus diameter was $22 \mathrm{~mm}$. Coronary angiography showed no critical stenoses in coronary vessels. Distance from aortic annulus to the ostium of left main coronary artery
(LMCA) was estimated to be $8 \mathrm{~mm}$. Angiography of iliac and lower limb arteries revealed a diameter of right and left common femoral artery at 9 and $11 \mathrm{~mm}$, respectively. The subject was discussed at a Heart Team meeting and scheduled for TAVI with a recommendation for femoral access.

The procedure was performed under general anesthesia and under TEE control. Right common femoral artery was properly punctured for index procedure. The calcified aortic valve was crossed with the support of a 6 French Amplatz left 1.0 diagnostic catheter. The wire was exchanged for a superstiff one. Balloon aortic valvuloplasty was performed using a 12 French $20 \times 50 \mathrm{~mm}$ balloon under pacing at $180 \mathrm{bpm}$. Afterwards, a successful implantation of a $26 \mathrm{~mm}$ Edwards-Sapien valve (Edwards Lifesciences, Irvine, CA, USA) under pacing at $180 \mathrm{bpm}$ was performed.

Control aortography showed a good flow in the right coronary artery and no flow in the left main coronary artery. Seconds later, there was a pressure drop to $0 \mathrm{~mm} \mathrm{Hg}$ and cardiac arrest. The subject was immediately resuscitated, and a temporary pacemaker in the right ventricle sustained the heart rhythm. Immediate coronary angiography of the left coronary artery with a Launcher (Medtronic Vascular, USA) 7 French Amplatz left 2.0 guiding catheter was per- 

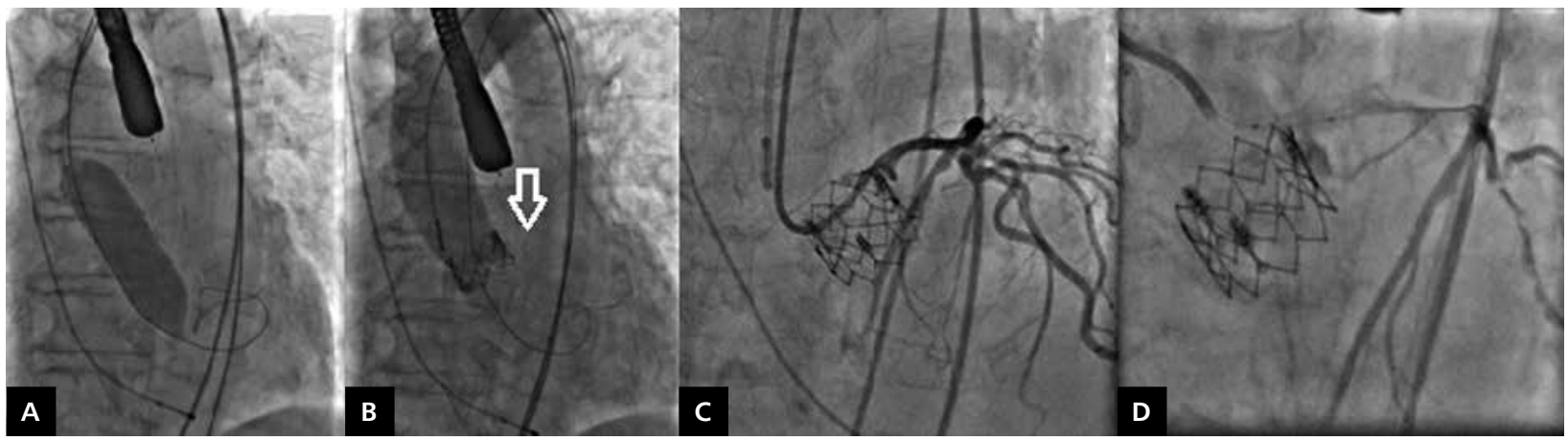

Figure 1. Transcatheter aortic valve implantation (TAVI) procedure and coronary angioplasty in a 92 year-old female; A. Balloon aortic valvuloplasty; B. Control aortography after TAVI in the left oblique anterior view revealing a flow in the right coronary artery and an occlusion of the left main coronary artery; C. Coronary angiography of the left coronary artery in the anteroposterior view; D. Bare-metal stent $4.0 \times 18 \mathrm{~mm}$ implantation within the left main coronary artery

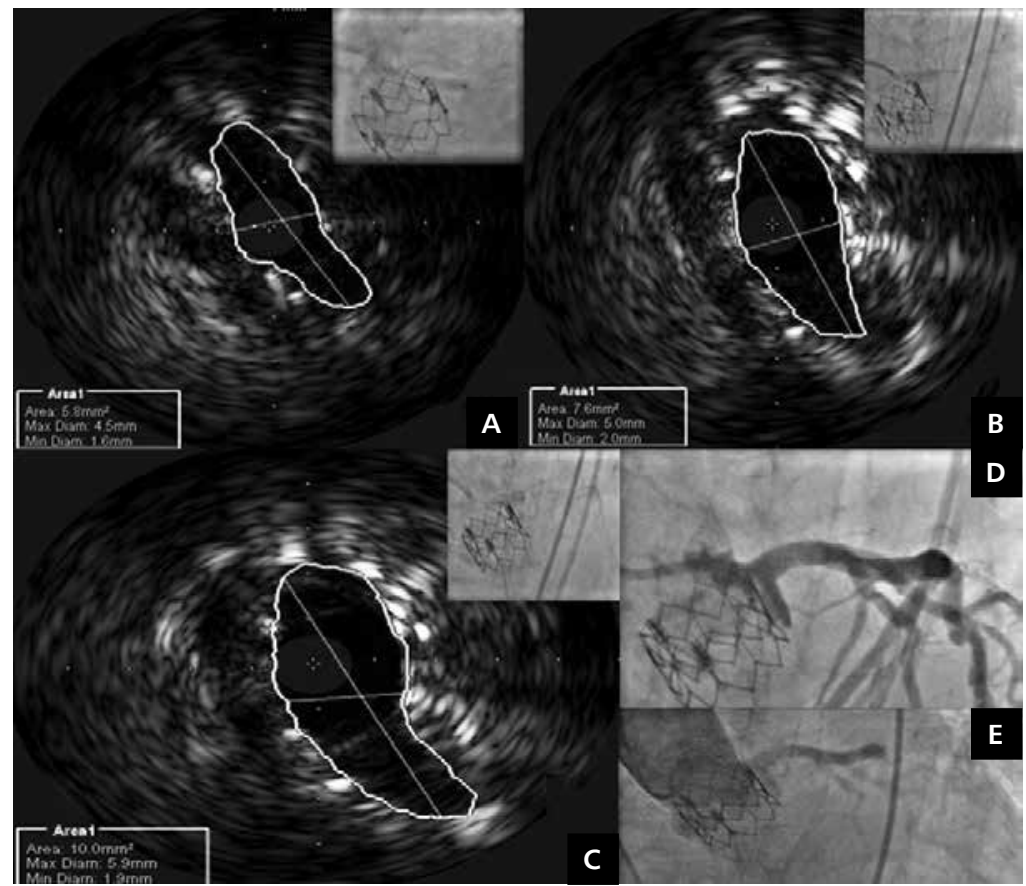

Figure 2. Coronary angioplasty and coronary intravascular ultrasound (IVUS) pullback in a 92 year-old female; A. First IVUS run after bare-metal stent implantation showing elliptical shape of the previously implanted stent and minimal lumen area of $5.8 \mathrm{~mm}^{2}$ and balloon postdilatation with $4.5 \times 15 \mathrm{~mm}$ noncompliant balloon; B. Control IVUS pullback revealing still elliptical stent shape and minimal lumen area of $7.6 \mathrm{~mm}^{2}$ and another bare-metal stent $4.5 \times 16 \mathrm{~mm}$ implantation; $\mathbf{C}$. Balloon postdilatation with a $5.0 \times 15 \mathrm{~mm}$ noncompliant balloon and control IVUS run revealing a minimal lumen area of $10 \mathrm{~mm}^{2} ; \mathbf{D}$. Control coronary angiography showing final result of the angioplasty; E. Control aortography showing good flow in the left main coronary artery

formed. There were difficulties in intubating the ostium of the LMCA. A soft 0.014-inch BMW (Abbott Vascular, USA) guidewire was inserted into the left anterior descending artery. A bare-metal stent $4.0 \times 18 \mathrm{~mm}$ was deployed at 20 atmospheres (Fig. 1). A coronary intravascular ultrasound (IVUS) pullback was performed showing the elliptical shape of the previously implanted stent and minimal lumen area (MLA) of $5.8 \mathrm{~mm}^{2}$. A balloon postdilatation with $4.5 \times 15 \mathrm{~mm}$ noncompliant balloon with 20 atmospheres was performed.
A control IVUS pullback was done revealing a still elliptical stent shape and MLA of $7.6 \mathrm{~mm}^{2}$. Another bare-metal stent $4.5 \times 16 \mathrm{~mm}$ at 20 atmospheres was deployed. Balloon postdilatation with a $5.0 \times 15 \mathrm{~mm}$ noncompliant balloon with 20 atmospheres was done. Another control IVUS run revealed a MLA of $10 \mathrm{~mm}^{2}$. Control coronary angiography and aortography showed a good final result of the angioplasty (Fig. 2). The patient was successfully discharged after ten days with no symptoms of angina. 
In conclusion, TAVI is associated with procedure-related complications such as valve embolisation, cardiac perforation and coronary occlusion, requiring rapid diagnosis and treatment. Short distance from aortic annulus to the ostium of LMCA $(<10 \mathrm{~mm})$ is a risk factor for acute LMCA closure and should probably be avoided.

Conflict of interest: none declared

\section{References}

1. Cribier A, Eltchaninoff $\mathrm{H}$, Bash A et al. Percutaneous transcatheter implantation of an aortic valve prosthesis for calcific aortic stenosis: first human case description. Circulation, 2002; 106 : 3006-3008.

2. Vahanian A, Alfieri O, Al-Attar N et al. European Association of Cardio-Thoracic Surgery; European Society of Cardiology; European Association of Percutaneous Cardiovascular Interven- tions. Transcatheter valve implantation for patients with aortic stenosis: a position statement from the European Association of Cardio-Thoracic Surgery (EACTS) and the European Society of Cardiology (ESC), in collaboration with the European Association of Percutaneous Cardiovascular Interventions (EAPCI). Eur Heart J, 2008; 29: 1463-1470.

3. Leon MB, Smith CR, Mack M et al. Transcatheter aortic-valve implantation for aortic stenosis in patients who cannot undergo surgery. N Engl J Med, 2010; 363: 1597-1607.

4. Smith CR, Leon MB, Mack MJ et al. Transcatheter versus surgical aortic-valve replacement in high-risk patients. N Engl J Med, 2011; 364: 2187-2198.

5. Stabile E, Sorropago G, Cioppa A et al. Acute left main obstructions following TAVI. EuroIntervention, 2010; 6: 100-105.

6. Saia F, Marrozzini C, Marzocchi A. Displacement of calcium nodules of the native valve as a possible cause of left main occlusion following transcatheter aortic valve implantation. J Invasive Cardiol, 2011; 23: E106-E109. 